\title{
Attachment Parenting among Middle-class Couples in Spain: Gendered Principles and Labor Divisions
}

\begin{abstract}
The time that middle-class fathers and mothers devote to care activities has significantly increased over the last two decades in Spain. In a context of increasingly widespread intensive and child-centered parenting styles, the attachment parenting movement draws on a genderessentialist interpretation of attachment theory to prescribe a series of practices that place great pressure on women's time, minds and bodies. Such burdens are likely related to the gendered division of household roles, but this issue remains largely underexplored in research. This paper aims to fill this gap in the literature by exploring the links between gendered interpretations of attachment parenting principles and gendered patterns of labor division. The methodological approach consists of 28 semistructured interviews conducted separately with mothers and fathers from heterosexual couples with professional or managerial jobs and children under three years of age. The findings show that the gender essentialist interpretation of the attachment relationship rather than the amount of attachment parenting performed seems more determinant of task segregation. Prolonged breastfeeding stands out as a major barrier to a more egalitarian division of tasks, even for couples who are critical of the gendered interpretation of the attachment figure.
\end{abstract}




\section{Introduction}

Recent studies in the Spanish context have shown that the dedication of fathers and mothers to care tasks has significantly increased, particularly among professional couples, rendering childrearing a more labor-intensive activity (Borràs, Ajenjo \& Moreno-Colom, 2018). The rising parental involvement in childcare among highly educated couples in Spain has been attributed to a cultural shift towards intensive mothering (IM) (Hays, 1996), although more qualitative research on this issue is needed (Borràs et al., 2018). This increase, which is consistent with international trends (Bianchi et al., 2012), has not entailed a more egalitarian division of paid and unpaid labor (Borràs et al., 2018). Recent studies have analyzed the mechanisms through which inequality develops during the transition to parenthood (Abril et al., 2015) and the conditions that may allow the maintenance of a more egalitarian division of domestic labor (Dominguez-Folgueras, Jurado-Guerrero, \& Botía-Morillas, 2018), but this topic remains largely underexplored.

Moreover, a particular version of IM-attachment parenting (AP) appears to be spreading in Spain. Despite a lack of empirical studies on the issue, the expansion of this parenting type can be indirectly gauged through its growing presence in the media, internet forums, and public debates $^{1}$. Inspired by the movement started in the 1990 s in the US and spearheaded by family physician William Sears, AP ideals seem to have reached Spanish society more recently through local medical figures. The publication of the book "Bésame mucho" (Kiss me much) in 2003 can be considered a milestone for the AP movement in Spain, and the author, pediatrician Carlos González, is becoming an increasingly importance reference and prominent media figure. 
AP prescribes a highly demanding and child-centered parenting style, which is consistent with the observed trends towards intensive parenting styles in advanced countries (Bianchi et al., 2012; Damaske, 2013). Furthermore, by drawing on a gender-essentialist interpretation of attachment theory, AP prescribes a series of practices that place enormous pressure on women's time, minds and bodies. Such strong requirements can certainly be expected to influence the gender division of household roles, but this issue has not yet been addressed in the literature. Aiming to fill this gap, this paper explores how parents with different attitudes towards gender roles may produce different gendered interpretations of AP principles and thus exhibit different patterns of labor division. To address this issue, 28 semistructured interviews were conducted separately with mothers and fathers from heterosexual couples with professional or managerial jobs and at least one child under three years of age. The sample was purposefully restricted to couples with a middle-class background given that previous studies in other European countries have suggested that AP is more widespread among this social group (Faircloth, 2013; Damaske, 2013).

The article is structured as follows. The first section introduces the paper's theoretical background by discussing the intersections between the concepts of IM and AP and hypothesizing how we expect AP to be related to gendered role divisions. The methodological approach is outlined in the second section. In the findings section, we analyze the couples' diverse approaches to AP and place them on a continuum representing different gendered interpretations of the key principle of AP: the importance of a parental figure of attachment and the nature of the attachment bond. We identify two ideal types defining the extremes of this continuum and show how different positions along it relate to different gendered patterns of labor division. The results are discussed in the concluding section. 


\section{Theoretical framework}

The 1990s witnessed an increased interest in research on parenting in the context of increasingly diversified practices in Western Europe and the United States, which raised concerns about the implications for gender equality among different parenting styles. A stream of literature has addressed the diffusion of IM ideals and their implications for women's wellbeing (Douglas \& Michaels, 2004; Hays, 1996). According to Hays' (1996) definition, which we adopt here for our purposes, IM is characterized by three main principles: a) mothers are inherently better parents; b) mothering should be child centered; and c) children should be considered sacred, delightful, and fulfilling to parents. This concept shows an important degree of overlap with AP; while IM has a longer tradition as an analytical concept in the sociological literature, AP refers to a parenting movement and defines a more specific set of principles and practices.

AP was coined and popularized as a parenting current in the 1990s through the books of William and Martha Sears, a family physician and his wife, who stressed the need for extensive mother-child physical contact to ensure the child's healthy physical, emotional and moral development. Their precepts derive from a particular interpretation of attachment theory in developmental studies, which has a long tradition that can be traced back to the early work of John Bowlby and Mary Ainsworth. In Sears' interpretation, the bond between mother and child is considered primary, especially during the first one or two years of life, and the father or other potential caregivers play only a supporting role. Despite Attachment Parenting International, a reference organization for the AP movement, announcing on its website that they embrace "the diversity of family structures and values all people in a child's life who actively foster a strong attachment relationship with the children in their care", this statement coexists with the 
idea that securing the relationship with the mother allows a baby to develop strong healthy bonds with other important people in his or her life.

In effect, the mother's primary role as caregiver is pervasive throughout the eight basic principles of AP established by this organization, from which a set of privileged practices is derived. Five of these principles appear to be the most important for the relationship between AP and gendered role divisions: a) Feeding is understood as an act of love and a means of strengthening the bond with the child. Cue breastfeeding (on demand or baby-led breastfeeding) beyond one year of age is recommended. Nursing is considered a main way of comforting the child; b) Sensitivity with regard to the child's needs implies that parents should understand their child's inner rhythms and schedule around them, and that they should prioritize the child's needs over their own. c) Adopting a nurturing touch means providing affection through direct physical contact (skin-to-skin, massages, baby wearing using a soft carrier); d) Recognizing the child's needs for reassurance and comfort during the night just as during the day means avoiding solitary sleeping and adapting sleeping arrangements to the baby's sleep patterns. These arrangements include co-sleeping and bed-sharing; e) Full-time caregiving by one or both parents is privileged to guarantee "consistent and loving care". Inhome care and including the baby in personal and couple activities is strongly encouraged. Day-care facilities and separations of more than one night are strongly discouraged for children under three.

This set of principles largely coincides with the second and third characteristics of Hays' (1996) definition of IM: b) mothering should be child centered; and c) children should be considered sacred, delightful, and fulfilling to parents. Moreover, although they could be formulated on a gender-free basis in theory, these principles are generally applied through enactment of an essentialist construction of motherhood, which attributes a privileged and unique bond with the 
child to the mother. In this sense, AP also largely corresponds to the first characteristic of IM: a) mothers are inherently better parents. In short, we can argue that adoption of AP principles will necessarily lead to intensive parenting practices because AP prescribes a highly demanding and child-centered parenting style. Moreover, this intensive parenting will likely become a synonym for IM since the key figure and the bond of attachment are generally interpreted in a highly gendered manner. This gendered interpretation can have strong implications for gender relations in the household, but this subject remains largely underexplored in the literature. Studies on IM have shown the unmanageable time and psychological pressures involved in rising to the level of what is considered "good mothering" (Douglas \& Michaels, 2004; Rizzo, Schiffrin, \& Liss, 2013; Sutherland, 2010), revealing the 'cultural contradictions' (Hays, 1996) that shape women's moral dilemmas regarding their work and family choices. In turn, research on AP has mostly addressed the essentializing arguments underpinning women's narratives of 'natural mothering' (Bobel, 2002; 2007; Faircloth 2011, 2013). However, studies analyzing how the adoption of AP ideals and practices relates to gendered patterns of labor division are lacking.

We can hypothesize how such a relationship may take shape. Studies have shown that the expansion of IM ideals has led women, even those employed full-time, to increase the amount of time they devote to childcare, which has become more intense and emotionally demanding (Damaske, 2013). AP can be viewed as a particular version of IM, the salient precepts of which (cue and prolonged breastfeeding, full-time home-based care, scheduling around the child's needs) can place even greater demands on women's time, minds and bodies. In this sense, we would expect couples who fully embrace AP ideals to adopt a gender role division where women are mostly invested in childcare. Especially during the first years of a child's life, we would expect these women to fully withdraw from the labor market and to be devoted to 
childrearing full-time, with consequent implications for their employment trajectories and financial independence. At the same time, we have previously argued that AP does not necessarily need to be interpreted in a gender essentialist manner. We can therefore hypothesize that couples with more egalitarian gender attitudes who adopt AP practices will ultimately engage in intensive parenting but that this responsibility will be more equally shared between the male and female partners. In short, the paper's main goal is to explore how parents with different attitudes towards gender roles may produce different gendered interpretations of AP principles and thus exhibit different gendered patterns of labor division.

In analyzing the gendered patterns of labor division, we look at both housework and care labor as fundamental areas for delimiting gender boundaries in the household (Hochschild, 1989). Housework includes routine household tasks such as cleaning, shopping, cooking and laundry, while care labor refers to tasks more directly related to caring for a child (feeding, changing, bathing, or putting the child to sleep). We also consider the management involved in both type of activities. From a doing gender perspective (West \& Zimmerman, 1987), parents do gender insofar as they enact a given understanding of femininity and masculinity in the tasks they choose to take on (or not). We know from the literature that housework and care labor are associated with different and changing gendered meanings, which are fundamental in demarcating the shifting gender boundaries in the household. Routine housework tasks have traditionally been perceived as strongly feminine (Sullivan, 2013). Mothers taking primary responsibility for childcare has been associated with the understanding that they are more efficient and nurturing parents (Coltrane, 1989). However, the changing involvement of fathers and mothers in different activities may also be accompanied by shifting gendered meanings attributed to certain tasks. In this sense, examining the boundaries of normative behavior allows the identification of points of change when these meanings shift (Benjamin \& Sullivan, 1999). 
Therefore, the concept of gender boundaries is useful in that it "simultaneously expresses a basic commonality in the divisions between the sexes, while at the same time permitting the analysis of differences and change in patterns of gender experience" (Benjamin \& Sullivan, 1999: 799). From this perspective, the paper analyzes not only how different approaches to AP are related to given patterns of labor division but also how these divisions are assigned a gendered meaning.

\section{Methods}

A qualitative research strategy was used to address both the factual and the discursive dimensions of the effects of the transition to parenthood on the interviewees' everyday lives. The sample was restricted to couples with a middle-class background (defined on the basis of educational level and job type) given that previous studies in other European countries have suggested that AP is more widespread among this social group (Faircloth, 2013; Damaske, 2013). Twenty-eight interviews were conducted with 14 heterosexual couples with high educational levels (university degrees) and professional or managerial jobs (see table A in the appendix), living in an urban context, Barcelona and its metropolitan area. We selected couples who had at least one child younger than 3 years of age given that children in this age range require the most intensive care and AP principles are stricter at this age; thus, the consequences for gender role division are likely to be more visible. Couples were contacted using a snowball technique with multiple entries. The author's personal networks were first mobilized, and we then asked the participants to provide further contacts at the end of their interviews.

The interviews included a set of questions on daily routines and how those routines were affected by the transition to parenthood. Informants were also asked about their expectations of and ideas about parenting prior to childbirth and the extent to which these expectations were 
met by their actual experiences as parents. The processes of decision-making around the division of housework and care and the couple's participation in employment were explored by probing their answers regarding everyday routines and their changes. We did not explicitly ask about AP ideals or practices, which emerged spontaneously in the interviews and were then further explored through probing. Interviews were conducted separately with each partner to avoid the constraints of joint interviews on individual reporting, to facilitate the emergence of potentially conflictual issues and to allow the identification of possible contradictions between the partners' accounts (Valentine, 1999). Interviews lasted from 55 minutes to 2 hours, with an average duration of 1 hour 20 minutes, and were conducted by one of the authors at a place of the interviewees' choice, generally in the couple's home.

A qualitative, thematic analysis of the interviews (Braun \& Clarke, 2006) was performed with Atlas.ti software (version 8.2.4). The process of hierarchical coding was the result of an abductive process of dialogue between the flexible theoretically derived guidelines and the inductive input of the analysis of the interviews. Interviews were first coded and analyzed vertically, that is, each interview was analyzed as an entity. We then conducted cross-sectional analyses to compare the experience of each participant with that of his or her partner. Finally, cross-sectional analyses were performed to identify similarities and differences across the couples. Interviews were conducted in either Catalan or Spanish. The excerpts quoted in the findings section have been translated into English.

\section{Findings}

AP was present in all of our interviewee's accounts. Some embraced it explicitly as a corpus of ideals and practices; several couples adopted some of its preceptive principles and practices without explicitly referring to AP as a coherent framework; and a few couples criticized the 
pressures that AP imposes on mothers but still implemented salient AP practices. These last couples were critical of a mother-centered interpretation of AP rather than of the AP principles themselves. In fact, none of the couples in our sample explicitly rejected AP principles.

Our findings show that it is not so much the amount of AP performed but the gendered interpretation of the key principle of AP - the figure and bond of attachment - that is more determinant of task segregation. Since our focus of interest was precisely the relationship between AP and labor divisions, we decided to classify the participants on a continuum representing the extent to which they identified with a more or less mother-centered interpretation of AP.

This continuum was defined on the basis of two ideal types positioned at each extreme (Figure 1): on the left are essentialist couples, who privilege the mother-child bond through arguments based on 'nature' or 'instinct'. On the right are critical couples, who question the fundamental principle that the mother needs to be the primary figure of attachment. Some couples identify more completely with the ideal types described. However, approximately half of the sample is situated somewhere between these two positions. Therefore, in the presentation of the findings, we build the argument mainly around the two main ideal types for the sake of analytical clarity while acknowledging that the differences between couples along the rest of the continuum are mostly a matter of degree.

It should also be noted that the (gendered) interpretations of AP often coincided for both members of the couple. This was particularly the case for critical couples, whose joint views appeared to be the result of a common reflection on the issue. More diversity in interpretations was found in the middle and the far left of the continuum, with women upholding more essentialist views than men. For graphical representation purposes, when couples agree in their 
views beyond the anecdotal, we represent them together and bonded by the symbol " $\&$ " on the continuum. When there are relevant differences, we represent them farther apart without the "\&" in between.

\section{Figure 1. Gendered interpretations of attachment parenting}

Essentialist

Critical

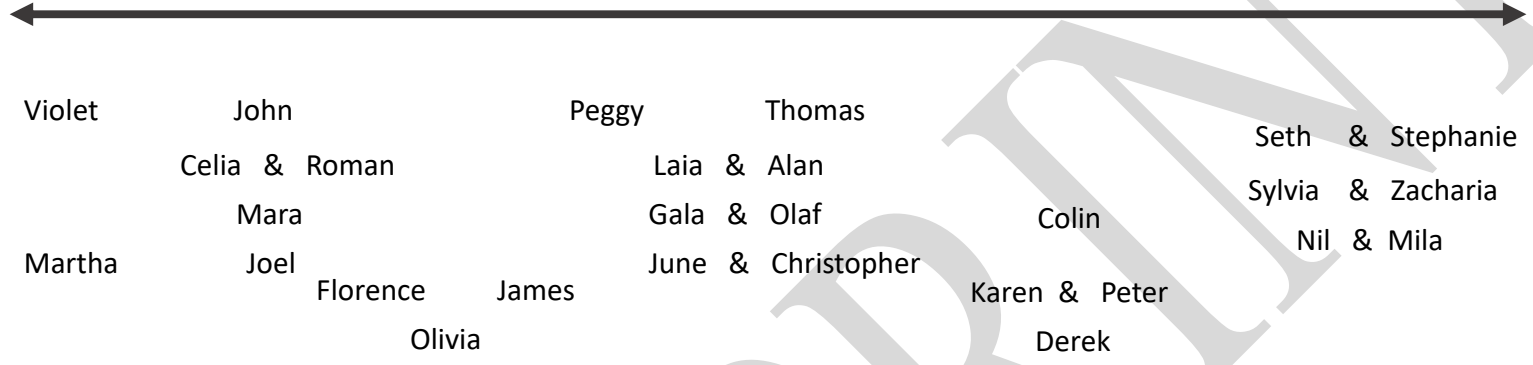

\section{Gendered interpretations of AP and AP practices}

On the left end of this continuum, we have essentialist couples who more strongly identify with the general principle of the importance of the continuous presence of a figure of attachment during the first years of a child's life to ensure their full personal and emotional development. The figure of attachment is in this type a synonym for the mother. In fact, it is the women in these couples who uphold the most essentialist interpretation, according to which the mother should provide this attached care. For Violet, the need for the mother's presence over the first years of life to guarantee the well-being of the child became an evident truth that she "learnt" during the first months after the birth of her daughter:

I was not aware that she needs me to be with her for three years, or at least two years, to be alright (Violet, 34, architect, self-employed part-time). 
These mothers attribute their primary role as attachment figure to the fundamental difference in the relation they - as opposed to the father - establish with their child. This difference is based on biological arguments; gestation, childbearing and breastfeeding are argued to produce a special and incommensurable bond between mother and child.

It's not only the 'breast.' I think the fact of giving birth... the fact that you do the gestation, that you give birth... (Violet, 34, architect, self-employed part-time).

It is beast-like, very animalistic, from the first minute, he could be a puppy and it would be the same, I could put him on my breast... (Celia, 36, industrial designer, unemployed).

Essentialist mothers emphasize their parenting practices as ensuing naturally and instinctually. They just need to do what "feels right". Indeed, some of these mothers also refer to AP as "natural childrearing". As anticipated, fathers in these couples do not express such a strong identification with AP ideals or an essentialist and biologically based gendered interpretation, but they explicitly assume a secondary role in childrearing:

I help, I give a hand to [Martha], if he has mommyness, I can't do much, so I do other things; I am kind of a satellite around the planet (Joel, 40, industrial chemist, employed part-time).

Over half of the couples are distributed somewhere between the poles of the continuum and adopt the precepts of AP to different extents. These couples do not refer explicitly to the AP principle of the figure of attachment, and they seem to be less aware of AP as a coherent framework. Moreover, the accounts of both partners appear to be more coincident than those of the couples representing the essentialist type. The justifications for the mother's primary 
role as caregiver in these couples are less about gender essentialism and the reification of the child-mother bond and more about the legitimation of the state of things. Parents do not argue that the mother necessarily needs to be the primary caregiver, but their greater "ability" or "effectiveness" with the child makes it more practical for her to be focused on the child:

With her [the mother], the girl stays calmer, because well, maybe she breastfeeds her and then she puts her to sleep more easily. I can make her sleep, [...] but I need to spend 15 or 20 minutes, and then she falls asleep, and then I can do things (Cristopher, 37, chief of logistics, employed full-time).

There are moments during the night, even if he [the father] gets up, children want their mother [...]. Especially if the mother is there. If I weren't there or if it was a single-parent household of just a man, for instance, the child would not look for their mother... When the mother is not there, there is no problem, but if she is there, it's "mom" totally, and there is little the dad can do" (June, 33, postdoctoral researcher, employed full-time).

Though these arguments may implicitly build upon a naturalization of women's caregiving abilities, they differ from Violet's and Celia's explicit essentialization in a way that is relevant for thinking about labor divisions. For interviewees defending essentializing arguments, women's primary caregiving role is a given for biological reasons. For participants using the "efficacy" argument, women's primary caregiving role is the state of things, but one could imagine that it could be otherwise. Actually, several fathers, such as Christopher, express some sense of frustration about not being more "able" themselves.

On the right end of the continuum, a few couples viewed the emergent AP ideals critically, and they explicitly reflected on the privileging of the mother-child bond as a potential threat to 
gender equality. The couples in this type support practicing a general idea of "attached care" or "respectful childrearing" but argue that both parents can act as attachment figures to the same extent:

I think that the child has to be with an attachment figure; you cannot leave them as if they were a car, parked somewhere... And this figure has to be the father and the mother, or the mother and the mother, and the father and the father, I don't know... But you cannot say it has to be the mother just because she gives birth (Sylvia, 37, lawyer, employed part-time).

These couples reported having reflected on these issues with their partners, and a joint analysis of their discourses indeed showed that they shared very similar views. For instance, both Zacharia and Sylvia speak of AP as a sort of increasingly widespread trend exerting an enormous pressure on mothers:

At first, we were super activists and then we realized that maybe this has gone too far, especially because of what it entails for the mother [...] All the inputs that I was receiving were like 'the link with the mother is sacred,' 'she needs you and only you'... And I said, 'Yeah, but I also need things, you know? (Sylvia, 37, lawyer, employed part-time).

I read one book by this guy, Carlos González, and it influenced me a lot [...]. Now I see it as a very dangerous book [... 'Wow, how beautiful the ideal world that the doctor presents, but he is a man telling women what they have to do.' [...] He is the unquestionable leader of the issue of the childrearing thing, which is fashionable... And if you don't like it, it looks as if you were a bad father and 
especially a bad mother, who socially is responsible for everything (Zachariah, 39, consultant, full-time).

Unexpectedly, the relationship between the different gendered interpretations of AP outlined above and the number or types of AP practices implemented by the couples is far from straightforward. We do observe that essentialist mothers refer most systematically to AP's key principles. In particular, they emphasize breastfeeding as an act of nurturing and bond establishment and implement cue breastfeeding for prolonged periods; they refer to sensitivity towards the child's needs and the need to schedule around the child's rhythms and to adapt sleeping arrangements to ensure safe sleep. However, on-demand prolonged breastfeeding, bed-sharing, and co-sleeping are also common practices among critical couples and couples in intermediate positions along the continuum. Actually, every couple in our sample practices one or both of these principles, and most reflect on the importance of listening to children's needs, respecting their rhythms and providing affection through direct physical contact. We do observe a main difference distinguishing essentialist couples from the rest. The practices of essentialist couples are closer to the ideal of full-time, home-based care provision during the whole first year of a child's life. For the remaining couples, the implementation of certain AP practices, especially prolonged breastfeeding, is compatible with a larger commitment to employment and with childcare services. In short, the main difference in our couples' practices concerns the fifth AP principle outlined above: the privileging of full-time, parental (maternal) home-based care. These differences certainly have direct and strong implications for the gender role division in the household but are not the only determinant of task segregation in domestic and care labor, as discussed next. 


\section{Gendered interpretations of AP and the gender division of labor}

Our analysis shows a clear link between gendered interpretations of AP and the type of employment arrangements adopted by our interviewed couples. Essentialist mothers substantially reduced their employment commitments after the end of maternity leave by cutting their working hours in half, working from home with a very reduced workload if working as a freelancer or drawing on their unemployment benefits to provide home-based care. Most of the remaining mothers reduced their employment commitments to a lesser extent, by reducing working hours, decreasing their workloads, or cutting down on business trips or remote work. In turn, most fathers returned to employment immediately after the end of their paternity leave and remained employed full-time. The main exception was fathers in critical couples who all reduced their employment commitments significantly during the first year of the child's life.

Regarding the division of domestic and care labor, most of our couples showed non-traditional patterns but still practiced a gendered task division. In this respect, essentialist women and women in intermediate positions assumed the majority of childcare tasks while their partners performed significant amounts of domestic labor, albeit to different degrees. In some of these couples, fathers even performed larger shares of domestic work than mothers. Critical couples stood out in their struggles to achieve egalitarian arrangements, that is, to equally share all kinds of household labor. In short, we can identify a relationship between the couples' gender interpretations of $\mathrm{AP}$ and the type of employment arrangements and patterns of division of domestic and care labor that they follow. To illustrate this link, we next draw on the examples of four couples as cases representing different positions along the continuum: Violet and John for the essentialist type; Sylvia and Zacharia and Seth and Stephanie for the critical couples ${ }^{2}$ and June and Christopher as a couple with an intermediate position. 


\section{Violet and John: upholding a gendered labor division}

Violet decided to go back to work five and a half months after childbirth only after agreeing with her boss to work from home and with a reduced workload. Violet's daily schedule is organized around her daughter's needs: she wakes up when her daughter does, and if the child takes a nap, then she sleeps too. Being an architect and doing work that is project-based, she does not work for a fixed number of hours, but adapts her working time to what she considers her daughter's needs. Her partner works a continuous work day and comes home by 4 p.m. to take care of their daughter, which is when she starts working, but only once she has ensured that her daughter is comfortable with him:

Then we try to do the transition, [...] the three of us are together for a while, and when they are fine, I leave (Violet, 34, architect, self-employed part-time).

The secondary role attributed to the father and his lack of capability as a caregiver stands out in her account. Even when her partner is at home, she interrupts work when she feels her daughter needs her:

I don't work four hours exactly; I work when I can. [...] It depends on the day, she is calmer and plays more, or she is more nervous, or... it depends... [...] If she needs me, I go. I mean... If John tries... he tries to handle it, you know? But if I see that it takes too much... the advantage of being here is that I can go (Violet, 34, architect, self-employed part-time).

If the daughter seems to need a walk in the park, Violet stops working and the three go together because it "feels" right. Indeed, Violet has not yet separated from her daughter, who is now nine months old, further than being in separate rooms in the same house, representing a case 
where the principle of coherent, full-time, home-based (maternal) care is followed strictly for a prolonged period after birth. Violet also adopts a whole set of other practices that compose the full spectrum of AP practices, including skin-to-skin contact, breastfeeding on demand and bed-sharing as a means of comforting the child. This example illustrates how AP applied in its most gender-essentialist version clearly overlaps with IM.

At the same time, such implementation does not need to be a synonym for a traditional division of labor. Indeed, Violet and John are one of the couples exhibiting a sort of specialization of the mother in caring and the father in housework. In the evening, while she puts the daughter to sleep, he does the lunch dishes and prepares dinner. The boundaries establishing a gendered division of tasks are no longer the traditional boundaries, but they continue to delimit a division of male and female spaces, tasks and responsibilities, thus redefining gender boundaries. Moreover, in this case, the mother feels more strongly about her role as primary caregiver. Violet does not want her partner to be more involved in her daughter's care. She would see this as a sort of invasion of a sphere that belongs to her:

When they tell me that my fourth month of maternity [leave] can be shared... Well, sixteen weeks, and John can take two weeks, I say no, I don't want you to take it away from me, sorry! (Violet, 34, architect, self-employed part-time).

In contrast, John appears less committed to AP principles and a gender-essentialist interpretation of AP, as reflected in Figure 1. While he does mention having decided with his partner to do "respectful childrearing", he relativizes the decision by arguing that "you never know if you get it right". While for Violet staying at home to care for her daughter was a decision based on what felt was right, for John it was the result of her having more flexibility 
at work than him. In this type, it paradoxically appears to be the woman who more intensely upholds a gendered division of roles in the household.

\section{June and Christopher: inertially sliding into intensive mothering}

June went back to work as a researcher when her maternity leave ended six months after childbirth. The child was looked after by the maternal grandmother until she started day care at the age of one. June now works from home one day a week, and she leaves work earlier two days a week to pick up her daughter from day care. The grandmother and the father do one additional day each. Neither of the members of the couple identify themselves explicitly with AP as a framework and did not consider providing full-time home-based parental care. However, they refer in general terms to a "respectful" approach to childrearing, and they implement an intensive, child-centered parenting style, including prolonged breastfeeding and co-sleeping. This case shows that female full-time employment is not necessarily incompatible with intensive parenting practices, although the degree of this intensity will certainly differ.

June and Christopher share the overall workload of domestic and care labor relatively equally, but the division of tasks still follows a gender logic: he assumes the largest share of domestic labor (cooking, grocery shopping), while she is dedicated to caring for the child.

Before we used to do it more... shared, [...] And now, we distribute it in a way that he cooks... He looks after me, and I look after the baby girl. Especially until now, because she is very little and it's basically mom, mom... (June, 33, postdoctoral researcher, employed full-time).

This pattern of division of domestic and care labor is similar to that observed in Violet and John's case. However, June and Christopher do not justify this specialization based on 
essentialist but on pragmatic arguments. June is argued to be more able or effective in calming the child when she is upset or helping her fall asleep, which leads to her being in charge of the evening and nighttime child routines, while the father prepares dinner, cleans the dishes or takes out the trash. Prolonged breastfeeding stands out as a crucial factor accounting for the alleged greater effectiveness in this case. Nursing is viewed as the easiest and quickest means to comfort the child; therefore, June's undertaking of such a task is simply more convenient.

All of the three main characteristics of IM as defined by Hays (1996) can be identified in June and Christopher's case, even in the absence of strong and explicit identification with AP. This case suggests that implementation of one of the most salient practices of AP, prolonged breastfeeding, will drive a couple to easily adopt a pattern of intensive investment of the woman in childcare. However, as discussed next, the couple's critical attitude towards the gendered assumptions behind AP affects how much breastfeeding influences gendered role divisions.

\section{Sylvia and Zacharia - Seth and Stephanie: struggling to share it all}

Both Sylvia and Zacharia and Seth and Stephanie inverted their roles in employment at some point after childbirth, that is, the mother's engagement in the labor market was more important than that of the father. This inversion allowed the father to be involved in everyday routines early in the transition to parenthood. These couples have the most egalitarian patterns of division of domestic and care labor, that is, they are closest to an equivalent distribution of the overall workload and show limited gender segregation across different tasks. This was also the case for Nil and Mila, the third couple falling into the critical ideal type.

In Sylvia and Zacharia's case, she went back to employment after the end of her maternity leave with a minor reduction in working time. At Sylvia's initiative, Zacharia asked for a leave of absence, which was not an option for her because of the employer's opposition. Zacharia's 
employer offered him the opportunity to work remotely part-time. This arrangement lasted until their daughter was 10 months old. Later, Zacharia increased his working time and organized his schedule to be able to spend as much time with his daughter as his partner. Both parents agree that this forced role inversion was fundamental to achieving a more egalitarian division of domestic and care labor. Spending time alone with the child forced the father to make his own decisions and implement his own routines, allowing him to become an active co-parent:

The good part of me increasing my working hours, $[\ldots]$ is that we have found an equilibrium, $[\ldots]$ The day he is with Laura [the child], he is alone with her, when before, they were never alone. Thus, he always leaned more on me because I knew what had to be done. Instead, now, because he is alone... they have their own dynamics, and when he is there, he does the laundry, the shopping; whatever he has to do the day he is there (Sylvia, 37, lawyer, employed part-time).

Zacharia's involvement is facilitated and encouraged by Sylvia, who, far from upholding the existence of a unique mother-child relationship, argues for the need for an attachment figure regardless of gender, as illustrated by previous quotations. Despite his increased involvement, Zacharia is aware of the persistence of inequalities in their division of domestic and care labor:

The things Sylvia complains more about, and I am fully aware that she is right, are things that are really exhausting and invisible, $[\ldots]$ all the planning, about the food, about Laura's [the child] medical visits, about which things need to be brought to school $[\ldots]$ It's not $50 \% / 50 \%$ entirely. It's the ideal that we pursue and that we both want, but we have inertia and periods of adjustment... (Zachariah, 39, informatics consultant, employed full-time). 
Like June, Sylvia also managed to combine working with prolonged breastfeeding (until her daughter was 2 years of age). However, for Sylvia this was perceived as a very arduous task and one of the most important pressures imposed by AP:

The thing of attachment parenting, for mothers, I think that it is... it is unmanageable, I mean, it is unmanageable. [...]. The day I stopped breastfeeding Laura [child], I told her 'I can't anymore, I can't, I mean, I can't' anymore... (Sylvia, 37, lawyer, employed part-time).

A slightly different case is that of Stephanie and Seth. Seth drastically modified his employment commitments following the birth of both children by quitting jobs with which he was not particularly happy to be more involved in their care.

For me it was a liberation, because I used to arrive home at 7 in the evening, sometimes later, and I was with the baby for the leftover time. Beginning at 7 in the evening it's the worst time for babies, you do not interact with them in any way, and I did not feel useful (Seth, 32, secondary education teacher, employed parttime).

At the time of the interview, he was working at $30 \%$ and his partner $60 \%$, both having made the decision to earn less and to have more time to be with their daughters. Seth actively fought to be as active and present as his partner, while she did not particularly encourage his involvement. Instead, Stephanie's account reveals an awareness of her potential "gatekeeping behavior" (Allen \& Hawkins, 1999) ${ }^{3}$ and her struggles to avoid it. Stephanie struggles with not being in full control because her partner takes responsibility for a large amount of management: 
It is true that sometimes I have some conflict, that my mother used to control everything, and here I don't control everything at all. [...] Occasionally I have seen that it gives me a bad mood... of thinking, 'it's me who should be controlling it,' you know? [...] I think it's difficult to break [gender roles] on both sides (Stephanie, 29, teacher, employed part-time).

Stephanie is aware that there are certain forms of self-imposed or internalized conditionings that have implications for an egalitarian division of tasks. She acknowledges that although the children's dependence on her has diminished as they have grown, she still does not feel right about leaving them, although her partner encourages her to take time for herself:

Sometimes Seth tells me 'Stephanie, they are not going to stop loving you if you leave for an afternoon'. I do have this pressure of omnipresence... [...] Now they are older, and we start leaving them more, and it is difficult for me. [...] It is hard to dissociate yourself and to say 'What am I interested in? Ok, so I will leave this afternoon and I do something I am interested in.' (Stephanie, 29, teacher, employed part-time).

Prolonged breastfeeding stands out in her account as a conditioning in which distinguishing between subjective and objective dimensions is difficult:

This disconnection you can make, you know, Seth went cycling for 5 days in the summer, for the first time. But me... obviously Seth was telling me 'Do it too, we will manage.' But there is this pressure 'No, she is still breastfeeding every day...' With certain things, [...] it's like, an attachment. It's also my thing; I mean, I could be stronger and say, 'Look, there's no breast' (Stephanie, 29, teacher, employed part-time). 
In short, these two couples identified with the general ideal of "attached" care and implemented key AP practices such as cue breastfeeding or co-sleeping. At the same time, they denied the secondary role of the father as a figure of attachment. In fact, both fathers and mothers verbalized their awareness of how their practices and everyday inertia potentially led to gender inequalities, and prolonged breastfeeding stood out as an important conditioning in this respect. Overall, although they also implemented intensive parenting styles, these couples departed the most from the IM ideal that mothers are inherently better parents.

\section{Discussion and conclusions}

The paper has explored how different gendered interpretations of AP principles by parents with different role attitudes produce different gendered patterns of labor division ${ }^{4}$. The paper contributes to the literature by showing the complexity of the relationship between gendered interpretations of the figure of attachment, the AP practices that are actually implemented and the (re)definition of gender boundaries in the division of labor.

The findings showed the pervasiveness of AP in the couples' discourses, either because they embraced AP to different extents or because they criticized the gendered interpretation of the key principle of AP: the importance of a figure and bond of attachment. Our case studies were placed on a continuum representing the extent to which the couples identified with a more or less mother-centered interpretation of AP.

On one extreme end of the continuum, we found interviewees who more explicitly embraced AP principles and practices based on an essentialist construction of motherhood. Similar to Bobel's $(2002,2007)$ "natural mothers," they described a mother-child relationship that is incommensurable to the child and father rapport because of biological differences. Notably, the mothers in these couples advocated more strongly their primary role as caregivers, inspired by 
a "cultural" or "difference" feminism that favors women's unique experiences. They reproduce the ideological and material inequalities embedded in the institution of motherhood through what Bobel $(2002,2007)$ called the "the paradox of natural mothering," i.e., their simultaneous emphasis on choice and nature. Their practices were closest to the ideal of full-time homebased (maternal) care, and they adopted the full spectrum of AP practices, resulting in the most intensive mothering style. In turn, couples in the middle of the continuum expressed a more general understanding of "attached" or "respectful childrearing" and adopted some of AP's associated practices. For most of these couples, the interpretation of the mother as the most effective parent and the dynamics of inertia resulted in mothers assuming the role of primary caregiver. However, demarcation of childcare as the mother's territory was less pronounced, and the intensive mothering style was compatible with a greater commitment to employment. Third, on the right side of the continuum, couples were explicitly critical of the reification of the mother-child bond and rejected the secondary role of the father as a figure of attachment. These couples showed the most egalitarian task division in terms of both overall workload and task segregation, and fathers adopted non-traditional patterns of labor market participation, which were compatible with the adoption of AP practices such as prolonged breastfeeding or co-sleeping.

Overall, these findings show that there is not a direct relationship between different gendered interpretations of AP and the number or type of AP practices implemented, but we did identify a link between the gendered interpretations of AP and the gender role division resulting from such practices. In short, the roles attributed to the mother and the father in such attached care rather than the amount of AP performed account for the gendered patterns of labor division. We found that essentialist couples adopt a clearer division of gender roles and are the only couples to exhibit patterns of full-time home-based maternal care for prolonged periods. The 
specialization of the mother in childcare in these households is generally countered to some extent by the father performing significant amounts of housework, in some cases even larger loads than the mother. Such a pattern of gender specialization in care versus domestic work is, however, not specific to essentialist couples: it was also observed in several other couples across the continuum, albeit with different intensities. Moreover, while essentialist mothers uphold this division, it is often viewed as a pragmatic arrangement by couples with intermediate positions, while critical parents attempt to overcome it.

This evidence shows that AP will easily although not inevitably develop into intensive mothering practices and gendered patterns of labor division. In prescribing an intensive parenting style that tends to attribute the primary bond of attachment to the mother, women will hardly escape the strong pressure that privileged practices impose on their minds, time and bodies, especially when the attachment principle is interpreted in a gender-essentialist manner. Moreover, although we did not observe a direct effect of the implementation of most AP practices on patterns of labor division, prolonged breastfeeding stood out as a major barrier to an egalitarian division of tasks, especially during the child's first year. All mothers in our sample breastfed for a prolonged period of time, albeit with diverse durations and intensities. Throughout the continuum, parents used nursing for comforting the baby out of either conviction or pragmatism. Consistent with Bobel's (2007) findings, we observed that when breastfeeding becomes the primary means of calming the baby or putting the baby to sleep, mothers are quickly viewed as irreplaceable, which leads to a gendered role division particularly during evening and nighttime routines. One could even argue that breastfeeding is less salient for determining task segregation in essentialist couples than for those who are further to the right on the continuum. For the latter, it is a main pragmatic factor leading women to be more dedicated to the children, while for the former it is just one more practice 
constituting the universe of the privileged child-mother bond. Critical couples are aware of such conditionings and attempt to overcome them.

The findings show that changes in gender relations can occur in a non-linear manner and vary across the domains of domestic tasks and care labor. Among our analyzed couples, we identified a redefinition of gender boundaries, especially for couples who more explicitly identify with an essentialist interpretation of AP. The patterns of division of domestic and care labor reflect significant progress in the division of housework, but they continue to define a stereotypical division of male and female spaces, tasks and responsibilities. The childcare domain is emphasized as the mother's territory, especially during the early years. This finding endorses Coltrane's (1989) idea that everybody is seen fit for housework, while mothers are viewed as the most competent caregivers.

At the same time, some of our couples show only minor task segregation both across and within housework and childcare activities, providing some hints about the conditions for achieving shared parenting. Critical couples are aware of the conditioning and inertia leading to a gendered role division and the need for a conscious and constant effort to overcome them. For fathers, the development of such an awareness is linked to their involvement in everyday routines early in the transition to parenthood. Reducing their employment commitments has allowed them to perform tasks that are more rigid and time-demanding and to spend time alone with their children. As shown in the literature on involved fathers (Craig, 2006; Rehel, 2014), alone father-child time has proven to be a key condition for achieving shared parenting.

Just as men need to be willing to share the responsibility for childcare and management of the household, mothers need to be ready to allow fathers to enter the caring sphere. Self-awareness of "gatekeeping behavior" and attempts to avert it are key conditions for shared parenting. 
Instead of attributing special skills to themselves, women in these couples allow and encourage their partners' involvement in childcare on equal terms. They are aware of their internalized conditionings and struggle with their feelings of guilt over not always being present or their fears of not being in full control. These findings are consistent with research showing that maternal beliefs about the father's role and maternal gatekeeping attitudes are predictors of actual paternal involvement (Fagan \& Barnett, 2003; McBride et al., 2005).

This study has certain limitations, including the small and socially homogeneous sample. Moreover, the specificity of the sample and the methodology used do not allow us to present these findings as representative of broader trends in the population. However, the paper's value lies, first, in revealing certain dynamics though which new parenting ideals may lead to complex and non-linear processes of change in gender relations and, second, in providing some insights into possible paths to achieving more egalitarian arrangements. Overall, shared parenting appears to be the result of both of conscious reflection and an everyday struggle to overcome gendered conditioning for the couples in our study. However, even when there is a shared awareness and willingness to overcome these barriers, social inertia may still prove difficult to overcome. Overall, this study highlights the achievement of gender equality as a daily and constant challenge.

\section{References}

Abril, P., Amigot, P., Botía-Morillas, C., Domínguez-Folgueras, M., González, M. J., JuradoGuerrero, T., ... Seiz, M. (2015). Ideales igualitarios y planes tradicionales: análisis de parejas primerizas en España. Revista Española de Investigaciones Sociológicas, 150, 322. 
Allen, S. M., \& Hawkins, Alan J. (1999). Maternal gatekeeping: Mothers' beliefs and behaviors that inhibit greater father involvement in family work. Journal of Marriage and the Family, 61(1), 199-212.

Benjamin, O., \& Sullivan, O. (1999). Relational Resources, Gender Consciousness and Possibilities of Change in Marital Relationships. Sociological Review, 47(4), 794-820.

Bianchi, M., Sayer, L.C., Milkie, M.A. \& Robinson, J.P. (2012). Housework: Who Did, Does or Will Do It, and How Much Does It Matter? Social Forces, 91(1), 55-63.

Bobel, C. (2007). Resisting, but Not Too Much: Interrogating the Paradox of Natural Mothering. In A. O’Reilly (Ed.), Maternal Theory. Essential Readings (pp. 782-791). Toronto, Canada: Demeter Press.

Bobel, C. (2002). The Paradox of Natural Mothering. Philadelphia, PA: Temple University Press.

Borràs, V., Ajenjo, M., \& Moreno-Colom, S. (2018). More Time Parenting in Spain: A Possible Change towards Gender Equality? Journal of Family Studies.

Braun, V., \& Clarke, V. (2006) Using thematic analysis in psychology. Qualitative Research in Psychology, 3: 77-101.

Coltrane, S. (1989). Household labor and the routine production of gender. Social Problems, $36(5), 473-90$.

Craig, L. (2006). Does father care mean fathers share?: A comparison of how mothers and fathers in intact families spend time with children. Gender \& Society, 20(2), 259-81.

Damaske, S. (2013). Work, family, and accounts of mothers' lives using discourse to navigate intensive mothering ideals. Sociology Compass, 7(6), 436-444. 
Dominguez-Folgueras, M., Jurado-Guerrero, T., \& Botía-Morillas, C. (2018). Against the Odds? Keeping a Nontraditional Division of Domestic Work After First Parenthood in Spain. Journal of Family Issues, 39(7), 1855-1879.

Douglas, S. J., \& Michaels, M.W. (2004). The mommy myth. New York, NY: Free Press.

Fagan, J., \& Barnett, M. (2003). The relationship between maternal gatekeeping, paternal competence, mothers' attitudes about the father role, and father involvement. Journal of Family Issues, 24(8), 1020-43.

Faircloth, C. (2013). Militant Lactivism?: Attachment Parenting and Intensive Motherhood in the UK and France. Berghahn Books.

Faircloth, C (2011). It Feels Right in My Heart': Affective Accountability in Narratives of Attachment. Sociological Review, 59(2), 283-302.

Hays, S. (1996). The cultural contraditions of motherhood. New Haven, CT: Yale University Press.

Hochschild, A. (1989). The second shift: working parents and the revolution at home. New York, NY: Viking.

McBride, B. A., Brown, G.L., Bost, K.K., Shin, N., Vaughn, B., \& Korth, B. (2005). Paternal identity, maternal gatekeeping, and father involvement. Family Relations, 54, 360-72.

Puhlman, D. J., \& Pasley, K. (2013). Rethinking maternal gatekeeping. Journal of Family Theory \& Review, 5(3), 176-93.

Rehel, E. M. (2014). When dad stays home too: Paternity leave, gender, and parenting. Gender \& Society, 28(1), 110-32. 
Rizzo, K. M., Schiffrin, H.H., \& Liss, M. (2013). Insight into the Parenthood Paradox: Mental Health Outcomes of Intensive Mothering. Journal of Child and Family Studies, 22(5), 614-20.

Sullivan, O. (2013). What Do We Learn About Gender by Analyzing Housework Separately From Child Care? Some Considerations From Time-Use Evidence. Journal of Family Theory \& Review, 5(2), 72-84.

Sutherland, J.A. (2010). Mothering, Guilt and Shame. Sociology Compass, 4/5, 310-21.

Valentine, G. (1999). Doing household research: Interviewing couples together and apart. Area, 31(1), 67-74.

West, C., \& Zimmerman, D.H. (1987). Doing gender. Gender \& Society, 1(2), 125-51. 


\section{Appendix}

\begin{tabular}{|c|c|c|c|c|}
\hline Couple & Age & Profession & Employment Status & Children \\
\hline Mila and Nil & 36 and 36 & Architect + App Designer & Full Time + Self-employed & 11 months \\
\hline Laia and Alan & 38 and 37 & Filmmaker + Sociologist & Self-Employed + Full Time & 4 months \\
\hline Mara and Colin & 37 and 36 & Art Manager + Publisher & Reduction+Full Time & 10 months \\
\hline Gala and Olaf & 38 and 36 & $\begin{array}{c}\text { Elementary Teacher }+ \text { Civil } \\
\text { Engineer }\end{array}$ & Reduction+Full Time & 2 and 5 years old \\
\hline Olivia and Derek & 37 and 37 & Industrial Designers & Full Time+Full Time & 8 months \\
\hline Martha and Joel & 37 and 40 & $\begin{array}{l}\text { Elementary Teacher + } \\
\text { Industrial Chemist }\end{array}$ & $\begin{array}{c}\text { Leave of } \\
\text { Absence+Reduction }\end{array}$ & 8 months \\
\hline Celia and Roman & 36 and 37 & Industrial Designers & $\begin{array}{l}\text { Unemployed+Self- } \\
\text { Employed }\end{array}$ & 6 months \\
\hline Violet and John & 35 and 34 & Technical engineer + architect & $\begin{array}{c}\text { Self-Employed Part-time }+ \\
\text { Full-time }\end{array}$ & 9 months \\
\hline June and Cristopher & 37 and 33 & $\begin{array}{l}\text { Chief of logistics }+ \\
\text { Postdoctoral researcher }\end{array}$ & Full-Time + Full-Time & 14 months \\
\hline Peggy and Thomas & 35 and 41 & $\begin{array}{l}\text { Research technician }+ \\
\text { Research technician }\end{array}$ & Part-time + Unemployed & $\begin{array}{l}18 \text { months and } 3 \text { and a } \\
\text { half years old }\end{array}$ \\
\hline Florence and James & 40 and 40 & Data analyst + Teacher & Reduction + Full-time & 2 years old \\
\hline Karen and Peter & 36 and 34 & $\begin{array}{l}\text { Relations with investors and } \\
\text { corporate development }+ \text { Chief }\end{array}$ & Reduction + Full-time & 3 years old +8 months \\
\hline Stephanie and Seth & 32 and 29 & Teacher + Teacher & Reduction + Part-time & 3 and 1 years old \\
\hline Sylvia and Zacharia & 39 and 37 & IT consultant + Lawyer & Full-time + Reduction & 3 years old \\
\hline
\end{tabular}

Table A. List of interviewees: Pseudonyms, Age, Profession, Employment Status, Number and Age of Children at the time of the interview 


\section{Endnotes}

1 As a paradigmatic example, see the public controversy that originated after Carolina Bescansa, a Spanish MP, brought her 6-month-old child to Parliament, arguing her right to practice 'attached care'.

${ }^{2}$ We decided to use two cases instead of one to exemplify the critical type because the quotations that were most illustrative of the arguments presented came from two different couples.

${ }^{3}$ Puhlman and Pasley (2013: 177) define maternal gatekeeping as "a set of complex behavioral interactions between parents, where mothers influence father involvement through their use of controlling, restrictive, and facilitative behaviors directed at the father's childrearing and interaction with children on a regular and consistent basis." When the term is used in this article, it emphasizes the dimensions of restriction and control, which may hinder or inhibit the father's participation and not the dimension of facilitation.

${ }^{4}$ In this sense, we would be arguing that it is the gendered interpretations of AP that lead to given patterns of labor division. Conversely, one could also suggest that couples with more egalitarian baseline labor divisions tend to interpret AP in a more gender-neutral manner. The relationship is likely to be more complex, with practices and interpretations mutually influencing each other as they evolve across the transition to parenthood and beyond. Disentangling this issue would require the analysis of longitudinal data, which points to future avenues for research. 